\title{
Signifikansi Pendekatan Kehati-hatian Dalam Pengaturan Organisme TransgeniK di Indonesia
}

\author{
Wahyu Yun Santoso ${ }^{1}$, Sunarto $^{2}$, Edhi Martono $^{3}$, Harry Supriyono $^{4}$
}

\begin{abstract}
Abstrak
Status megabiodiversity yang melekat pada Indonesia memberikan potensi besar akan pemanfaatan dan komersialisasi sumber daya alam hayati, yang salah satunya adalah sumber daya genetik. Tulisan ini hendak memaparkan penggunaan pendekatan kehati-hatian dalam pengaturan sumberdaya genetik. Utamanya membahas secara normatif pentingnya penerapan pendekatan kehati-hatian dalam pengaturan organisme transgenik di Indonesia. Pembahasan paper diawali dengan mendeskripsikan konsep pendekatan kehati-hatian, terutama dari sudut pandang CBD; konsep pengelolaan sumberdaya genetik Indonesia dan isu krusial yang ada; serta penerapan pendekatan kehati-hatian untuk pengaturan organisme transgenik di Indonesia.
\end{abstract}

Kata kunci: biodiversitas, sumberdaya genetik, bioteknologi, pendekatan kehati-hatian.

\section{Abstract}

The "Megabiodiversity" status adhere to the massive potency of Indonesian natural resources is having consequences in the management of natural resources, as well as its protection and preservation. One of the element of genetic resources is living modified

1 Departemen Hukum Lingkungan, Fakultas Hukum Universitas Gadjah Mada

2 Profesor Geografi Lingkungan, Fakultas Geografi Universitas Gadjah Mada

3 Profesor Ilmu Penyakit dan Tanaman, Fakultas Pertanian Universitas Gadjah Mada

4 Departemen Hukum Lingkungan, Fakultas Hukum Universitas Gadjah Mada 
organisms or transgenic organism. This paper discusses normatively the importance of precautionary approach in the genetic resources policy in Indonesia. The discussion in this paper is outlined with the description of the precautionary approach concept, particularly from CBD perspective; management of genetic resources in Indonesia and its crucial issues; and the implementation of precautionary approach for regulating transgenic organisms in Indonesia.

Keywords: biodiversity, genetic resources, biotechnology, precautionary approach.

\section{Pendahuluan}

Sebagai "megabodiversity country", keanekaragaman hayati merupakan aset penting bagi bangsa Indonesia, dan untuk dunia. Ratifikasi the Nagoya Protocol on Access and Benefit Sharing ${ }^{5}$ melalui Undang-Undang Nomor 11 Tahun 2013, menjadi bagian integral dari kerangka pengaturan Nasional tentang keanekaragaman hayati yang sekaligus mempertegas arti penting valuasi akan sumberdaya genetik. Hal ini menjadi signifikan saat potensi bioprospeksi ${ }^{6}$ berbanding lurus dengan risiko pencurian biodiversitas (biopiracy) kekayaan Indonesia. ${ }^{7}$

$5 \quad$ Nama lengkap dan resmi Protokol Nagoya adalah The Nagoya Protocol on Access to Genetic Resources and the Fair and Equitable Sharing of Benefits Arising from their Utilization to the Convention on Biological Diversity.

6 Bioprospeksi atau bioprospecting secara mudah dapat dikatakan sebagai eksplorasi atas keanekaragaman hayati baik untuk kepentingan ilmu pengetahuan maupun untuk komersil.Tidak ada definisi yang diterima secara internasional tentang bioprospeksi, namun dari pendapat secara umum yang dapat dirangkum, bioprospeksi merupakan upaya penelusuran atau penelitian dalam ranah biodiversitas, dan upaya pengambilan sampel dari organisme biologis untuk kepentingan riset pengetahuan maupun komersial. Memang menjadi sulit untuk membedakan antara riset terhadap sumberdaya genetik yang murni ditujukan untuk kepentingan ilmu pengetahuan, dengan riset yang dilakukan untuk aktivitas komersial. Karena seringnya penelitian untuk aktivitas komersial pun dilakukan dengan menggandeng institusi riset sebagai mitranya, dan demikian sebaliknya.

7 Biopiracy merupakan praktik eksploitasi sumber daya alam dan pengetahuan masyarakat tentang alamnya tanpa izin dan pembagian manfaat. Salah satu kasus biopirasi yang jelas isu maupun kronologisnya pernah terjadi pada awal tahun 2012. Saat itu Peneliti LIPI terlibat penemuan spesies baru tawon Megalara garuda dalam proyek kerjasama dengan University of California, Davis. Namun, ternyata dalam publikasi tentang temuan spesies tersebut tidak disebutkan peneliti Indonesia maupun wilayah Indonesia sebagai tempat diketemukannya spesies baru tersebut. (http://sains.kompas.com/read/2012/05/04/08175361/ LIPI.Akan.Selidiki-.Praktik.Biopiracy). 
Salah satu prinsip yang telah diadopsi di dalam pengaturan hukum keanekaragaman hayati adalah "precautionary approach" atau pendekatan kehatihatian. ${ }^{8}$ Pendekatan kehati-hatian menjadi prinsip utama yang perlu diterapkan dalam pengaturan kebijakan terkait penerapan teknologi yang berkembang cepat. Dengan loncatan kuantum yang terjadi di dalam perkembangan ilmu pengetahuan, setiap hari penemuan-penemuan baru sangat dimungkinkan untuk ditemukan dan memberi pengaruh signifikan dalam kehidupan. Namun demikian, bukti-bukti ilmiah (scientific evidence) yang ada seringnya bersifat tidak lengkap (incomplete) dan tidak pasti (uncertain). ${ }^{9}$ Penggunaan yang bijak, berhati-hati, serta bertanggungjawab dari keberadaan bukti-bukti ilmiah yang menjadi pangkal dari kemajuan teknologi inilah, termasuk bioteknologi, yang utama untuk diperhatikan sebagai suatu langkah kehati-hatian. ${ }^{10}$

Pendekatan kehati-hatian menegaskan bahwa dalam hal terdapat aras ilmiah yang cukup beralasan untuk mempercayai atau menduga bahwa suatu produk atau prosesnya tidak aman, produk atau proses tersebut tidak semestinya/diijinkan untuk diteruskan hingga ada bukti meyakinkan bahwa risiko yang ada cukup kecil atau berbanding jauh dengan kemanfaatannya. ${ }^{11}$ Pendekatan kehati-hatian juga dapat diterapkan pada suatu teknologi yang sudah ada ketika ditemukan satu bukti yang menunjukkan kenyataan bahwa teknologi tersebut (ternyata) lebih berbahaya dampaknya daripada yang diperkirakan sebelumnya. Contoh yang mudah dikenali pada konsep terakhir ini dapat meliputi bahaya rokok, CGCs, gas rumah kaca (greenhouse gasses), dan sekaligus produk rekayasa genetik.

Pada konteks ini, ketika risiko yang muncul kemudian diperkirakan lebih berbahaya dari sebelumnya, diperlukan suatu penelitian terpadu untuk mencari solusi atau upaya pencegahan dan penanganan dampaknya, dan untuk sementara

$8 \quad$ Konsep pendekatan kehati-hatian tercantum dalam Prinsip 15 Rio Declaration on the Environment and Development 1992 serta di dalam pembukaan (preamble) dari United Nations Convention on the Biological Diversity 1992 yang diratifikasi melalui UU Nomor 5 Tahun 1994.

9 Sekurangnya tiga poin ini yang menjadi alasan di dalam riwayat penerapan pendekatan kehati-hatian. Lihat Phillipe Sands, Principles of International Environmental Law: Second Edition, (UK: Cambridge University Press, 2003), hlm.269-270.

10 Peter T Saunders, Use and Abuse of Precautionary Approach. (Article on the ISIS submission to US Advisory Committee on International Economic Policy (ACIEP) Biotech. Working Group, July 13, 2000, hlm. 11.

11 Prinsip 15 Rio Declaration, sebagaimana dijelaskan oleh Per Sandin, The Precautionary Principle: From Theory to Practice (Stockholm: Mistra, 2002), hlm.5 
penggunaan teknologi tersebut semestinya dibatasi atau dihentikan untuk mengurangi ketergantungan. Lebih lanjut, jika ternyata bahaya yang ada dianggap cukup serius, prinsip kehati-hatian menekankan perlunya untuk menarik semua produk dan melarang penggunaannya atau melakukan moratorium untuk sementara waktu. ${ }^{12}$

Meskipun demikian, pendekatan kehatian-hatian tidak mengharuskan kepada pelaku usaha untuk menyediakan dan menunjukkan bukti-bukti yang mutlak tentang risiko dan tingkat keamanan dari produk atau proses baru dalam skema produksi mereka. Memang, ini akan menjadi satu permintaan yang tidak mungkin dilaksanakan karena akan mematikan penemuan teknologi. Karena pada prinsipnya, pendekatan kehati-hatian justru ditujukan untuk keadaan-keadaan ketika tidak terdapat kepastian ilmiah yang mutlak.

Secara konseptual, pendekatan kehati-hatian menjadi terobosan kebijakan yang dapat diterapkan untuk melakukan upaya konservasi dan perlindungan keanekaragaman hayati. Paper ini memaparkan secara singkat tentang konsep dan penerapan pendekatan kehati-hatian dalam kaitannya dengan perlindungan keanekaragaman hayati dari komersialisasi genetik di Indonesia.

\section{Biodiversitas dan Konsep Pendekatan Kehati-hatian}

Pendekatan kehati-hatian menjadi sangat penting dan mendesak saat dihadapkan pada situasi ketika terdapat pem-biar-an atau tidak cukupnya informasi untuk menangani suatu akibat atau dampak dari sesuatu teknologi atau invensi. Frank Knight, seorang ekonom dari University of Chicago, pada masa-masa awal pembahasan tentang pendekatan kehati-hatian berpendapat bahwa ketidakpastian (uncertainty) terutama yang "tidak terukur" (unmeasurable uncertainty) merupakan suatu hal yang umum dalam pengambilan kebijakan ekonomi. ${ }^{13}$ Knightian uncertainty, ${ }^{14}$ berlawanan dengan risiko yang merupakan

12 Peter T Saunders (2000). Op. Cit.

13 Knight dalam karya klasiknya di tahun 1921, Risk, Uncertainty, and Profit, membedakan antara risiko, sebagai sebuah kesempatan, dan ketidakpastian, sebagai kemungkinan yang tidak terukur. Menurut Knight, pembedaan itu penting karena risiko dapat dihitung dan dicegah atau dialihkan, sementara ketidakpastian merupakan jalan masuk dari kesempatan-kesempatan bisnis untuk menghasilkan keuntungan. Lihat David Cowan, Frank $H$. Knight. Great Thinkers in Economics (London: Palgrave Macmillan, 2016), hlm.27.

14 Ibid. Istilah Knightian Uncertainty ini ada dalam pembahasan Chapter 2. Knightian Uncer- 
ketidakpastian namun dapat diperkirakan (measurable or probabilistic uncertainty), yang menyebutkan bahwa perkiraan atau kemungkinan-kemungkinan tersebut dapat dilekatkan pada suatu peristiwa tertentu dan sekaligus dapat dihitung melalui ukuran-ukuran tertentu upaya penanganannya. Teori ini pula yang mendasari bahwa kerangka pikir yang tepat dapat diterapkan untuk menganalisa suatu ketidakpastian ilmiah (scientific uncertainty).

Ekonom umumnya berpikiran dan mencoba untuk mengelola ekosistem dan keanekaragaman hayati dalam suatu langkah kebijakan yang seoptimal mungkin, meskipun kompleksitas dari permasalahan yang ada di alam tidak memungkinkan optimasi hasil pada pencapaiannya. ${ }^{15}$ Pada tataran inilah, pemikiran untuk menjaga kelestarian alam dan keanekaragaman hayati yang ada, akan lebih tepat untuk menggunakan pendekatan safety rules atau peraturan-peraturan pengaman, yang dalam penerapannya diharapkan dapat mencegah proses kepunahan dari satu atau sekelompok spesies.

The Cartagena Protocol on Biosafety, ${ }^{16}$ sebuah perjanjian internasional yang mengatur tentang tata cara perpindahan lintas batas (transboundary movement), penanganan, dan penggunaan dari living modified organisms (LMOs), adalah salah satu produk hukum yang menekankan perlunya precautionary approach. Article 1 the Cartagena Protocol secara terang menekankan alasannya:

In accordance with the precautionary approach, contained in Principle 15 of the Rio Declaration on Environment and Development, the objective of the Protocol is to contribute to ensuring an adequate level of protection in the field of the safe transfer, handling and use of living modified organisms resulting from modern biotechnology that may have adverse effects on the conservation and sustainable use of biological diversity, taking also into account risks to human health, and specifically focusing on transboundary movements. ${ }^{17}$

"Sesuai dengan pendekatan kehati-hatian, termuat dalam Prinsip 15 Deklarasi Rio tentang Lingkungan Hidup dan Pembangunan, tujuan dari Protokol ini adalah tainty hlm 27-55.

15 Gaskell, G. et.al., Europeans and Biotechnology in 2005: Pattern and Trends, Eurobarometer 64. 3 (Brussels: European Commission D-G Research, 2006). Hlm 5

16 Protokol untuk Konvensi Keanekaragaman Hayati yang ditandatangani di Cartagena pada tahun 2000.

17 Pasal 1 Protokol Cartagena, lihat pada https://bch.cbd.int/protocol 
untuk memberikan dan menjamin level perlindungan yang memadai dalam hal perpindahan yang aman, penanganan, dan penggunaan dari organisme hidup modifikasi genetika yang dihasilkan dari bioteknologi modern, yang dapat memiliki dampak merugikan bagi konservasi dan pemanfaatan berkelanjutan biodiversitas, pertimbangan kesehatan manusia, dan secara khusus difokuskan pada perpindahan lintas batas".

Tujuan utama dari penerapan pendekatan kehati-hatian ini untuk menjamin adanya level perlindungan yang cukup dan layak dalam perpindahan, penanganan, serta penggunaan dari LMOs atau dalam terjemah resminya, Organisme Hasil Modifikasi Genetika (OHMG). Aplikasi OHMG terbukti menawarkan prospek yang positif untuk kesehatan manusia dan hewan yang lebih baik, peningkatan kualitas pangan, maupun juga dalam perlindungan lingkungan. Tanpa terkecuali, perhatian terhadap dampak dari aplikasi rekayasa genetika ini, terutama untuk Tanaman Pangan Rekayasa Genetika (TPRG) juga cukup tinggi di beberapa kalangan seperti konsumer, petani, masyarakat tradisional/adat, serta organisasiorganisasi lingkungan di seluruh dunia yang meningkat sejak akhir 1980an. ${ }^{18}$ Perhatian ini terutama difokuskan pada keseluruhan dampak yang mungkin timbul pada lingkungan, kesehatan, maupun kehidupan masyarakat di area pedesaan yang masih alami karena adanya komersialisasi genetik atas pangan dan pakan yang dihasilkan melalui rekayasa genetika ini.

Pendekatan kehati-hatian muncul dalam rumusan Prinsip 15 Deklarasi Rio ${ }^{19}$ yang dinyatakan bahwa:

"In order to protect the environment, the precautionary approach shall be widely applied by States according to their capabilities. Where are threats of serious or irreversible damage, lack of full scientifc certainty shall not be used as a reason for postponing cost-efective measures to prevent environment degradation" ${ }^{20}$

“Dalam rangka melindungi lingkungan, pendekatan kehati-hatian semestinya diterapkan secara menyeluruh oleh Negara sesuai dengan kemampuan masing-

18 INSIST, Politik Pangan: Perlu Perubahan Paradigma. (Yogyakarta: Penerbit INSIST, 2008), hlm 38.

19 Deklarasi Rio merupakan kesepakatan berisikan 25 prinsip yang dihasilkan dalam The United Nation Conference on Environment and Development yang berlangsung pada Tahun 1992 di Rio de Janeiro Brazil.

20 Prinsip 15 Rio Declaration. 
masing. Bahwa adanya ancaman bahaya yang serius atau kerusakan yang tidak dapat diperbaiki, kurangnya kepastian ilmiah yang memadai semestinya tidak menjadi alasan untuk menunda langkah-langkah yang efektif untuk mencegah penurunan kualitas lingkungan".

Dalam penerapannya, prinsip 15 Deklarasi Rio ini menekankan bahwa pendekatan kehati-hatian wajib untuk diterapkan dalam hal analisis risiko atas suatu kegiatan atau introdusir substansi tertentu menunjukkan adanya ancaman bahaya atau dampak yang cukup besar yang mungkin ditimbulkan, sementara jika didasarkan pada pembuktian terlebih dahulu dapat menjadi penghalang untuk pengambilan keputusan yang bersifat segera.

Per Sandin memberikan penafsiran atas konsep pendekatan kehati-hatian melalui 4 aspek: $:^{21}$

a. adanya threats atau ancaman karena suatu kegiatan yang berpotensi bahaya (potentially dangerous action);

b. ketidakpastian ilmiah (before scientific proof established);

c. adanya tindakan untuk membatasi, mengatur, atau mencegah; dan

d. sifat wajib dari tindakan tersebut (mandatory).

Adapun dari sekian rumusan yang ada tentang penerapan pendekatan kehatihatian, secara umum batasan pengertiannya mengerucut pada tiga hal, yaitu: sifat ancaman kerusakan lingkungan begitu serius dan bersifat tidak dapat dipulihkan (irreversible); terdapat ketidakpastian ilmiah (scientifc uncertainty); dan perlunya preventif, mencakup upaya pencegahan hingga biaya-biaya yang mendukung penanganan secara efektif (cost efectiveness). ${ }^{22}$

Pendekatan kehati-hatian dalam perkembangannya tidak hanya menjadi sekedar pendekatan umum terkait perlindungan lingkungan dan kesehatan, namun juga menjadi dasar pengaturan tentang risiko hingga sebuah pola kebijakan terkait riset keilmuan dan perdagangan. ${ }^{23}$ Beberapa versi yang berbeda dari prinsip

21 Per Sandin, Dimensions of the Precautionary Principle, (Human and Ecological Risk Assessment: An International Journal, Vol 5 No. 5 1999), hlm. 889-907, DOI:10.1080/10807039991289185 hlm. $890-891$

22 Philippe Sands, (2003). Op. Cit. Hlm. 269-271.

23 Kriebel, D., Tickner, J., Epstein, P., Lemons, J., Levins, R., Loechler, E. L., et al., The Precautionary Principle in Environmental Science. (Environmental Health Perspectives, 2001 Vol 109), hlm. 871-876 
ini juga bermunculan dari aspek pendekatan ekosentris hingga antroposentris, maupun dari aspek penghindaran risiko atau penanganan risiko yang ada. ${ }^{24}$ Bahkan beberapa pendapat membuat pembedaan dari aspek preskriptif atau petunjuk-petunjuk umum tentang prinsip pendekatan kehati-hatian dan aspek argumentatif atau alasan-alasan dibalik prinsip tersebut. ${ }^{25}$

Pada konteks ini, pendekatan kehati-hatian dapat digunakan sebagai satu opsi untuk mengelola risiko pada saat risiko tersebut telah diidentifikasi melalui analisis untung-rugi dan risiko (risk-cost-benefit analyses). Pada saat penerapannya, baik risiko maupun kemanfaatannya perlu diidentifikasi dan perkiraan atas risiko yang ada perlu dinilai berbasis pada bukti-bukti statistik serta dipantau secara berkala sebelum diputuskan hasilnya. ${ }^{26}$ Meskipun, terdapat satu kritisi dari Levidow yang mempertanyakan kegunaan dari kriteria efektivitas biaya ini karena ketika pendekatan ini diterapkan, justru semakin menegaskan bahwa berarti pengetahuan yang ada cukup tersedia untuk memperkirakan tingkat bahaya yang potensial sehingga memungkinkan adanya penilaian risiko berbasis efektivitas biaya tersebut. ${ }^{27}$

Pada situasi yang dipengaruhi oleh ketidakpastian dan kompleksitas, tidaklah mungkin untuk mendapat bukti ilmiah yang meyakinkan dan konklusif dari dampak negatifnya. Pada titik singgung inilah, pendekatan kehati-hatian menjadi sangat substantif karena pada saat terjadi ketidakpastian ilmiah, maupun perdebatan ilmiah tentang relevansi produk/teknologi dengan dampak negatifnya, risiko terhadap lingkungan atau kesehatan dapat menjadi isu minor yang dipertimbangkan, sehingga prinsip kehati-kehatian perlu diutamakan. ${ }^{28}$

Lebih lanjut, pada tataran preskriptif, pendekatan kehati-hatian semestinya menjadi dasar dari setiap aktivitas usaha/kegiatan yang dapat menimbulkan

24 C Weiss, Defining Precaution. (Environment, 2007, Vol 49. No. 8), hlm. 36-39.

25 P. Sandin, The Precautionary Principle and the Concept of Precaution. (Environmental Values, 2006 No. 13), hlm. 461-467.

26 M. Karlsson, The Precautionary Principle, Swedish Chemicals Policy and Sustainable Development. (Journal of Risk Research, 2006, No. 9), hlm. 337-360

27 L. Levidow, Precautionary Uncertainty: Regulating GM Crops in Europe. (Social Studies of Science, 2001, No. 31), hlm. 842-874.

28 Anne Ingeborg Myhr \& T. Traavik, Sustainable Development and Norwegian Genetic Engineering Regulations: Applications, Impacts and Challenges. (Journal of Agricultural and Environmental Ethics, 2003, No. 16), hlm. 317-335 
risiko bahaya atau dampak negatif. Ketika sebuah aktivitas usaha berpotensi menimbulkan ancaman bahaya pada kesehatan manusia atau lingkungan, pendekatan kehati-hatian wajib diterapkan meskipun penyebab dari ancaman bahaya maupun kausalitasnya tidak dapat dijelaskan secara ilmiah. ${ }^{29}$

Pendekatan kehati-hatian secara khusus difokuskan untuk mengetahui dan mengatasi problem kenihilan data pada saat pengambilan keputusan (problem of incertitude in decision-making).$^{30}$ Karena secara tradisional, metode kuantitatif seperti instrumen statistik atau prediksi tingkat kesalahan dapat memetakan ketidakpastian dan variabel yang ada, namun tidak semua aspek uncertainty dapat dijangkau melalui metode ini. ${ }^{31}$ Berbasis pada pendekatan sumber serta tipe ketidakpastian, terdapat pembedaan antara (a) linguistic uncertainty dan (b) incertitude. ${ }^{32}$ Linguistic uncertainty lebih dimaksudkan karena ketidakpastian yang diawali dari ketidakpastian data awal, atau secara mudah dari aspek bahasa saja sudah uncertain. Sedangkan incertitude lebih menekankan pada situasi terdapatnya kekurangan kepahaman ilmiah atau tidak lengkapnya deskripsi dari suatu peristiwa, sehingga dasar untuk menentukan kemungkinan-kemungkinan lain yang relevan juga tidak cukup kuat. ${ }^{33}$

Poin yang tertera pada bahasan di atas cukup krusial karena uncertainty atau ketidakpastian, terlebih pada komersialisasi genetik, dapat terjadi karena (i) novelty atau kebaruan dari aktivitas penerapannya bioteknologi, ${ }^{34}$ atau (ii) tidak lengkapnya deskripsi dari mekanisme atau proses yang ada. Lebih lengkapnya, terkait dengan OHMG, ketidakpastian menjadi sangat relevan jika dikaitkan pada aspek-aspek sebagai berikut: ${ }^{35}$

29 Anne Ingeborg Myhr, A Precautionary Approach to Genetically Modified Organisms: Challenges and Implications for Policy and Science, (Journal of Agriculture and Environment Ethics, 2010, 23:501-525). Hlm. 504

30 Ibid.

31 Ibid. Hlm. 506

32 Ibid. Hlm.510

33 Ibid. Hlm. 511-512

34 Bioteknologi berkembang sangat cepat, yang mana meninggalkan gap yang cukup lebar dengan kesiapan hukum dan kesiapan - penerimaan masyarakat. Pengembangan di dalam bioteknologi dilakukan pada level sel, yang mana, tingkat kebaruan sangat terbuka, meski untuk satu obyek yang sama.

35 Anne Ingeborg Myhr, (2010). op. cit. hlm. 516 
a. Adanya perubahan substantif pada OHMG atau produk turunannya. Struktur DNA dari organisme yang dimodifikasi merupakan struktur yang kompleks, sehingga implikasinya ekspresi genetis yang dibawa dapat jadi menimbulkan efek yang tidak diduga sebelumnya.

b. Efek sekunder yang timbul dari introduksi gen termodifikasi di lapangan. Beberapa contoh yang ada menunjukkan bahwa introdusir gen baru di lapangan sangat rentan dalam menimbulkan hama baru.

c. Adanya perubahan pada interaksi alam dan respon lingkungan (daya dukungnya). Introdusir OHMG jelas akan menimbulkan interaksi dengan organisme lain, sehingga kondisi lingkungan yang berbeda, termasuk karena adanya perubahan iklim, dapat mempengaruhi tingkat persistensi dari OHMG itu sendiri.

\section{Konsep Pendekatan Kehati-hatian dalam Pengaturan Organisme Transgenik $^{36}$}

Basis perdebatan umum yang sering terjadi, pada pendukung mengklaim bahwa organisme transgenik, yang terutama nampak pada tanaman pangan dan produk pakan hasil rekayasa genetika, dibutuhkan Dunia untuk mengatasi ancaman kelaparan; kurangnya ketersediaan pangan; kemiskinan di masa depan; dampak perubahan iklim; hingga pada alasan bahwa selain aman, TPRG dapat meningkatkan produksi pertanian. ${ }^{37}$ Pada sisi yang berseberangan, terutama organisasi non pemerintah (ornop) merasa bahwa isu risiko yang ada jauh lebih besar, dan sekaligus adanya skeptisme bahwa motivasi produsen yang senyatanya hanya untuk mencapai kepentingan ekonomi semata. ${ }^{38}$

36 Isitlah transgenik yang berasal dari trans-genetic, merupakan istilah populer yang disematkan pada OHMG. Istilah OHMG sendiri merupakan istilah legal formal yang diadopsi oleh Indonesia untuk menterjemahkan LMOs yang tercantum dalam Protocol Cartagena.

37 Gaskell, et.al, (2006).Op. Cit. Hlm. 8

38 Ibid. Di Indonesia, ornop memberi perhatian dalam organisme transgenik memiliki kecenderungan yang sama, yaitu skeptisme dan sekaligus "penolakan" terhadap produk transgenik. Memang yang menjadi permasalahan adalah isu ini masih menjadi isu minor di negara berkembang seperti Indonesia. 
Pada konteks negara maju seperti di Amerika maupun di Eropa, publik memahami adanya keberadaan OHMG ini dan berbagi perhatian yang sama terkait aspek sosio-ekonomis serta aspek biodiversitas. ${ }^{39}$ Beberapa riset yang dilaksanakan oleh komunitas-komunitas sosial, seperti komunitas konsumen di Amerika, mengisi diskursus ini dengan isu risiko dari $\mathrm{OHMG}^{40}{ }^{40}$ sementara para ilmuwan justru berbeda pandangan tentang ada tidaknya risiko nyata dari dampak yang merugikan terhadap kesehatan dan lingkungan. ${ }^{41}$

Penilaian risiko atas TPRG selama ini telah menghasilkan produk-produk kebijakan yang berbeda tergantung pada apakah institusi pengambil kebijakan terkait memiliki dan memahami cukup bukti ilmiah sebagaimana halnya ketidakpastian ilmiah yang ada. Hal ini berpengaruh pada munculnya dua kubu yang sama-sama kuat, pertama yang mendukung signifikansi dari bukti ilmiah mengingat risiko yang mungkin ditimbulkan, serta yang kedua lebih mendukung didasari atas poin kemanfaatan yang ada. Terutamanya, poin pembahasan utama ada pada peran dari pendekatan kehati-hatian ini dalam penilaian risiko serta proses manajemen dari komersialisasi genetika yang terkadang menimbulkan kontroversi. ${ }^{42}$

Penerapan pendekatan kehati-hatian juga mengharuskan adanya pengetahuan atau bukti ilmiah minimal untuk dapat mengalaskan signifikasi dari pencegahan bahaya atau ancaman bahaya tersebut. Bukti ilmiah minimal ini juga perlu didokumentasikan dengan metodologi ilmiah sebelum prinsip kehati-hatian dapat diterapkan. Sehingga dapat dikatakan, bahwa dalam hal bahaya atau ancaman bahaya tersebut murni sebatas hipotesis atau imajinasi semata, dengan ketiadaan indikasi ilmiah apapun terkait potensi bahayanya, pendekatan kehati-hatian tidak dapat diterapkan. ${ }^{43}$

39 Perbedaan tingkat kepahaman publik sangat berbeda antara negara maju dengan negara berkembang. Isu ini juga menjadi alasan mendesaknya suatu konsep besar dalam kerangka pengaturan OHMG di Indonesia.

40 I. De Melo-Martin \& Z. Meghani, Beyond Risk. (EMBO Reports, 2008 No. 9), hlm. 302-308. Dapat diunduh pada http://www.ncbi.nlm.nih.gov/pmc/journals/118/

41 Dalam tulisannya, Andow menyinggung tentang perubahan aspek dalam penilaian risiko atas tanaman transgenik. Utamanya diperluas dari sekedar non-target species, hingga ke local environment. Perluasan dalam environmental assessment ini sendiri menimbulkan di antara akademisi. Lihat D. A Andow \& C Zwahlen, Assessing Environmental Risks of Transgenic Plants. (Ecological Letters, 2006, 9: 196-214), hlm. 197-198.

42 Anne Ingeborg Myhr, (2010). Op. Cit. Hlm. 505

43 Ibid. 
Meskipun demikian, kriteria apa yang dapat diterima sebagai bukti ilmiah untuk dasar penerapan precautionary approach ini belum dibedakan dan didefinisikan secara tegas. Sebagai contoh pada Pasal 15 ayat (1) Protokol Cartagena disebutkan bahwa:

"Risk assessments undertaken pursuant to this Protocol shall be carried out in a scientifically sound manner... Such risk assessments shall be based, at a minimum, on information provided in accordance with Article 8 and other available scientific evidence in order to identify and evaluate the possible adverse effects of living modified organisms on the conservation and sustainable use of biological diversity, taking also into account risks to human health". ${ }^{44}$

"Penilaian risiko berdasarkan Protokol ini harus dilakukan dengan tata cara yang tepat secara ilmiah... Penilaian risiko tersebut harus dilandaskan, sekurangnya, pada informasi yang tersedia sesuai dengan Pasal 8 dan bukti ilmiah lain yang tersedia untuk mengidentifikasi dan menilai potensi dampak merugikan dari organisme hidup modifikasi genetika pada konservasi dan pemanfaatan berkelanjutan biodiversitas, dan mempertimbangkan risiko pada kesehatan manusia".

Bagaimana menerjemahkan "available scientific evidence" atau "bukti ilmiah yang tersedia" akan tergantung pada pengalaman keilmuan yang dimiliki oleh para ahli yang di dalam suatu negara. Salah satu contoh kasus yang pernah terjadi di Uni Eropa dapat menjadi satu rujukan yang bagus dalam memahami konteks penerapan pendekatan kehati-hatian ini. Bahwa setelah adopsi dari the EU Directive 90/220 pada tahun 1990, perselisihan serius terjadi antara the European Council dengan otoritas-otoritas nasional berkaitan dengan bukti-bukti ilmiah yang diperlukan dalam penerapan precautionary measures. ${ }^{45}$ Perselisihan ini berujung pada dua putusan penting terkait dengan penggunaan OHMG dan pelepasannya di Uni Eropa. Pertama, Dewan Menteri dari the European Council menyetujui adanya moratorium komersialisasi genetik dari OHMG pada bulan Juni 1999. Kedua, Uni Eropa mengeluarkan kebijakan baru dalam "membaca"

44 Article 15 (1) the Cartagena Protocol on Biosafety

45 EEA: European Environment Agency. Late Lessons from Early Warnings: The Precautionary Principle 1896-2000, (Brussell; 2002) http://reports.eea.eu.int/environmental_issue_report_2001_22/ 
Directive 90/220/EEC. ${ }^{46}$ Peraturan baru yang telah direvisi sekaligus menggantikan peraturan yang lama, EU Directive 2001/18/EC, ${ }^{47}$ yang secara tegas memasukkan precautionary principle pada pasalnya dan menambahkan persyaratan yang lebih ketat untuk persetujuan OHMG. Sebagai tambahan pada tahun 2000, the European Commission mengeluarkan satu communication paper yang menjelaskan pendekatanpendekatan apa yang diperlukan dalam menerapkan prinsip kehati-hatian, yang menegaskan bahwa kebijakan lingkungan di Eropa juga didasarkan dari prinsip tersebut sebagaimana dinyatakan pada Pasal 174 (2) Piagam Uni Eropa. ${ }^{48}$

Permintaan atas adanya "available scientific evidence" juga menimbulkan ambiguitas pada redaksional Protokol Cartagena itu sendiri, terutama jika diperbandingkan dengan yang dinyatakan pada Pasal 10:

"Lack of scientific certainty due to insufficient relevant scientific information and knowledge regarding the extent of the potential adverse effects of a living modified organism on the conservation and sustainable use of biological diversity in the Party of import, taking also into account risks to human health, shall not prevent that Party from taking a decision, as appropriate, with regard to the import of the living modified organism in question as referred to in paragraph 3 above, in order to avoid or minimize such potential adverse effects". ${ }^{9}$

"kurangnya kepastian ilmiah dikarenakan tidak cukupnya informasi ilmiah dan pengetahuan yang relevan mengenai tingkat potensi dampak merugikan dari organisme hidup modifikasi genetika pada konservasi dan pemanfaatan berkelanjutan biodiversitas dari Negara importir, dan mempertimbangkan risiko terhadap kesehatan manusia, tidak membatasi Negara untuk membuat putusan, sewajarnya, terkait impor tersebut, untuk menghindari atau mengurangi potensi dampak merugikan".

Pasal ini memberikan penegasan bahwa sangat dimungkinkan adanya ketidakcukupan informasi ilmiah yang relevan terkait dengan dampak negatif

\footnotetext{
$46 \quad$ Ibid.

47 CEC, European Council Directive 2001/18/EC, http://eur-lex.europa.eu/legal-content/EN/ TXT/?uri $=$ celex $\% 3 \mathrm{~A} 32001 \mathrm{~L} 0018$

48 CEC, Communication From the Commission on the Precautionary Principle, 2000, http:// europa. eu.int/comm/dgs/health_consumer/library/pub/pub07_en.pdf

49 Article 10 the Cartagena Protocol on Biosafety
} 
yang potensial, yang sekaligus merefleksikan sebuah kesadaran bahwa tidak cukup hanya pada kuantitas dari informasi ilmiah saja, tapi juga kualitas informasi ilmiah yang perlu diperhatikan dalam penilaian suatu risiko. Penafsiran dalam Pasal 10 Protokol Cartagena ini juga nampak pada komunikasi EC tentang prinsip kehatihatian $^{50}$ dan laporan dari UNESCO ${ }^{51}$ yang sama-sama menekankan pentingnya kuantitas dan kualitas dari informasi ilmiah. Pada konteks ini, penerapan pendekatan kehati-hatian tidak hanya ditentukan oleh jumlah informasi yang ada, namun juga macam kepahaman ilmiah yang sudah diketahui tentang suatu risiko bahaya dan adakah kekurangan dari informasi tersebut.

Dari dokumen komunikasi EC, prinsip pendekatan kehati-hatian perlu diterapkan pada saat terdapat dasar pertimbangan yang beralasan (reasonable ground for concern) dan oleh karena itu dapat melegitimasi putusan-putusan dan tindakantindakan yang diambil, terutama pada saat kepahaman ilmiah tentang dampak negatif yang ada hanya dimiliki oleh sebagian atau jumlahnya sangat terbatas. Sedangkan pada versi Laporan UNESCO, kondisi untuk dapat menerapkan prinsip kehati-hatian adalah adanya bahaya yang secara ilmiah masuk akal tetapi memiliki ketidak pastian (harm that is scientifically plausible but uncertain). Sehingga, dapat dikatakan bahwa kedua versi penafsiran dari precautionary approach dari dokumen-dokumen tersebut mengakui bahwa prinsip kehati-hatian dapat diterapkan pada saat terdapat kemungkinan timbulnya dampak negatif yang tidak dapat diperkirakan waktunya, atau dengan bahasa mudahnya: dampak negatif secara ilmiah masuk akal untuk terjadi, tapi keterkaitan antara aktivitas usaha dengan dampak yang ada belum cukup buktinya.

Meskipun pada tataran teoretis dan regulatif sudah cukup jelas dan tegas, pada kenyataan di lapangan, peran prinsip kehati-hatian ini dalam penilaian risiko dan pengelolaan OHMG menjadi satu obyek perdebatan dan kontroversi publik yang sangat panas. Dari pihak yang menolak, beralasan bahwa penerapan prinsip kehati-hatian menambah beban penaatan hukum dalam penggunaan OHMG, sehingga mengurangi kemanfaatan inovasi, membatasai pemanfaatannya secara

$50 \quad$ Ibid.

51 UNESCO COMEST, The Precautionary Principle, (Paris, 2005) http://unesdoc.unesco.org/ images/0013/001395/139578e.pdf 
global, dan sekaligus menjadi disinsentif untuk meningkatkan penelitian di aspek bioteknologi. ${ }^{52}$

Pendapat lain juga menyatakan bahwa tidak ada satupun definisi dari prinsip kehati-hatian yang menjelaskan secara spesifik dari intervensi yang diperlukan serta tidak memperhatikan aspek keseimbangan antara risiko dengan manfaat yang ada, ${ }^{53}$ sebagaimana juga kurangnya pendekatan untuk identifikasi risiko yang muncul dari kebijakan pajak impor yang ada dan kemungkinan menjadi penghambat bisnis dalam hal prinsip kehati-hatian diterapkan. ${ }^{54}$ Lebih lanjut lagi, prinsip kehati-hatian semestinya tidak diterapkan pada proses pengambilan keputusan (decision-making) karena adanya metode ilmiah kredibel (sound scientific methods) yang menawarkan dasar yang sangat tepat dan hati-hati dalam pemberian informasi ke pengambil keputusan..$^{55}$

Sementara di sisi lain, pendukung prinsip kehati-hatian termotivasi untuk meningkatkan prosedur keamanan yang kompetitif dengan penerapan prinsip ini, sekaligus memberi penegasan antara kepentingan lingkungan dan kepentingan bisnis dalam pengambilan keputusan. Meskipun sebenarnya rerata kritikan terhadap prinsip kehati-hatian ini hanya didasarkan pada misinterpretasi semata, ${ }^{56}$ karena pada dasarnya ketiadaan kepastian dan sekaligus rasionalitas ilmiah-lah yang menjadi alasan penerapan prinsip ini. ${ }^{57}$ Sementara semestinya hal yang lebih layak untuk diperdebatkan bukan pada bagaimana menerapkan prinsip kehatihatian, karena sangat teknis, tetapi lebih ke pada saat dan pada batasan apa pendekatan kehati-hatian diperlukan..$^{58}$

52 J. Morris, The Relationships Between Risk Analysis and the Precautionary Principle. (Toxicology, 2002) hlm 181-182.

53 C. Weiss, (2007). Op. Cit. Hlm. 36-39.

54 J. D Graham, \& J. B Wiener. The Precautionary Principle and Risk-Risk Tradeoffs: A Comment. (Journal of Risk Research, 2008 No. 11), hlm. 465-474

55 D. M.,Byrd \& R. Cothern, Introduction to Risk Analysis. A Systematic Approach to Science-Based Decision Making. (Rockville US: MD Government Institutes, 2000). Hlm. 25-27.

56 P. Sandin., (2006). Op.Cit.Hlm 465

57 Starling, Risk, Precaution and Science: Towards a More Constructive Policy Debate. (EMBO Reports, 2007, Edition 8), hlm. 309-315.

58 Wickson, F., Gillund, F. and Myhr, A. I. Treating Nanoparticles with Precaution: The Importance of Recognising Qualitative Uncertainty in Scientific Risk Assessment. dalam K. Kjølberg, F. Wickson (Eds.). Nano Meets Macro, Social Perspectives on Nanoscience and Nanotechnology. (US: Stanford Publishing., 2010), hlm. 176-179 
Secara khusus, pendekatan kehati-hatian untuk OHMG memerlukan "pandangan" baru terhadap ilmu pengetahuan yang menyokong penilaian risiko dan manajemen dalam penggunaan dan pelepasan OHMG. Hal ini menekankan bahwa perlu adanya identifikasi piranti-piranti praktis untuk dapat mendisain penelitian yang berorientasi pada pendekatan kehati-hatian dan sekaligus mengeksplorasi pentingnya bukti ilmiah yang berbasis kehati-hatian ini dalam pengambilan putusan dan kebijakan. ${ }^{59} \mathrm{Hal}$ ini sekaligus memerlukan pandangan kritis mengenai seberapa mungkin (reliable) data yang dapat didapatkan, dan apakah data tersebut dapat mewakili ketercukupan dari permasalahan yang sedang diinvestigasi untuk mengurangi insiden yang mungkin timbul akibat dampak negatif yang terjadi setelah adanya komersialisasi genetik. ${ }^{60}$

\section{Isu Krusial dalam Pengaturan Organisme Transgenik di Indonesia}

Implementasi pendekatan kehati-hatian meminta adanya tanggungjawab dari para pihak (pengekspor) untuk menunjukkan bahwa OHMG yang bersangkutan aman. Sehingga, pada penerapannya, rerata Negara mengaplikasikan pendekatan kehati-hatian secara kasuistis (case-by-case) dan bertahap (step-by-step). Prosedur kasuistis meminta adanya evaluasi ilmiah wajib dari setiap notifikasi adanya OHMG. Sedangkan prosedur bertahap memfasilitasi adanya perkembangan yang progresif dari OHMG dengan mengevaluasi dampak lingkungan yang ada dari proses pelepasan OHMG. Tujuan dari penerapan kedua prosedur ini adalah untuk membentuk praktik pembelajaran yang memungkinkan baik pengekspor maupun otoritas negara untuk mengumpulkan informasi ilmiah yang diperlukan. Sebagai tambahan, di Uni Eropa, pengekspor juga harus menyerahkan dokumen tentang program pemantauan (monitoring program) yang berisikan tentang rencana pemantauan lingkungan yang akan diterapkan setelah komersialisasi OHMG tersebut dilakukan. ${ }^{61}$

59 Anne Ingeborg Myhr, (2010). Op. Cit. Hlm. 516

60 Nielsen, K. M., \& Myhr, A. I. Understanding the Uncertainties Arising from Technological Inventions in Complex Biological Systems: The Case of GMOs. dalam T. Traavik \& L. C. Lim (Eds.), Biosafety Frst: Holistic Approaches to Risk and Uncertainty in Genetic Engineering and Genetically Modified Organisms. (Trondheim: Tapir Academic Press, 2007). hlm. 107-123.

61 CEC. Ibid. 
Satu hal yang cukup menjadi hambatan dalam penerapan pendekatan kehatihatian ini adalah menentukan beban pembuktian dan sekaligus beban tanggung jawab dari masing-masing pihak. Sebagai contoh, bagaimana dapat diyakinkan bahwa pengembang OHMG telah mengikuti prioritas prosedur penelitian yang ketat untuk mencegah dan mendeteksi adanya efek berbahaya? ${ }^{62}$ Pada perkembangan saat ini, penerapan tanggung jawab (liability) atau jaminan finansial berbarengan dengan persetujuan bersyarat dan uji coba skala luas dapat menjadi sarana untuk menjamin adanya tanggung jawab dari pengembang OHMG. Pembebanan tanggung jawab juga dapat ditambah dengan penilaian keamanan OHMG oleh tim ahli, yang mengharuskan pengembang OHMG untuk melakukan uji coba dan menunjukkan hasilnya ke komite ahli, atau mengharuskan untuk melakukan uji coba pada lembaga akademis yang terakreditasi. ${ }^{63}$

Selain itu, sebagaimana tertuang dalam pembahasan sebelumnya, salah satu isu krusial dalam penerapan pendekatan kehati-hatian ini adalah kemungkinan adanya ketidakcukupan informasi ilmiah yang relevan terkait dengan dampak negatif yang potensial. Kuantitas dan kualitas informasi ilmiah mengenai OHRG di Indonesia masih menjadi akses eksklusif sedikit pihak saja. Sementara untuk informasi publik masih kurang ketersediaannya.

Mengingat keunikan dari OHMG dan sekaligus keanekaragaman hayati itu sendiri, tingkat ketidakpastian (uncertainty) yang ada, dapat jadi sangat tinggi dan bervariasi. Praktik baik yang ada pada pengaturan kewajiban dan tanggungjawab pelaku usaha untuk berhati-hati dalam pemanfaatan OHMG di Eropa disinggung di atas sebagai konsep rujukan. Indonesia menaruh perhatian terhadap bioteknologi melalui dukungan peraturan diantaranya Peraturan Pemerintah Nomor 21 Tahun 2005 tentang Keamanan Hayati Produk Rekayasa Genetika Peraturan Pemerintah ini dibuat atas dasar pendekatan kehati-hatian dan mengacu pada Protokol Cartagena tentang Keamanan Hayati yang telah diratifikasi Indonesia melalui Undang-Undang Nomor 21 Tahun 2004 tentang Pengesahan Cartagena Protocol On Biosafety To The Convention On Biological Diversity. Penerapan protokol keamanan hayati yang tertuang di dalam Protokol Cartagena dilakukan Balai Kliring Keamanan Hayati (BKKH) yang merupakan perangkat dari Komisi Keamanan

62 Anne Ingeborg Myhr, 2010. Op. Cit. Hlm. 510

63 Ibid. 
Hayati.BKKH digunakan untuk memfasilitasi konsultasi publik terhadap hasil pengkajian OHMG.

Keamanan hayati OHMG dimaksudkan bahwa OHMG bersangkutan tidak mengganggu, merugikan dan/atau membahayakan kesehatan manusia, keanekaragaman hayati, dan lingkungan. Sesuai dengan amanat dari Protokol Cartagena, terdapat tiga uji keamanan hayati yang harus ditempuh oleh suatu OHMG sebelum dapat diperkenalkan ke pasar (komersialisasi) yaitu uji keamanan lingkungan, uji keamanan pangan, dan uji keamanan pakan.

Sementara, dari aspek pencegahan pencemaran dan/atau kerusakan lingkungan hidup, penilaian risiko lingkungan menjadi salah satu solusi yang dapat diterapkan sesuai prinsip pendekatan kehati-hatian ini. Sebagaimana diamanatkan di dalam UU Nomor 32 Tahun 2009 tentang Perlindungan dan Pengelolaan Lingkungan Hidup (selanjutnya disebut dengan UU Nomor 32 Tahun 2009), bahwa dalam beberapa usaha/kegiatan yang memiliki uncertainty tinggi dalam dampaknya, perlu menambahkan satu kajian risiko lingkungan selain kewajiban kajian dampak lingkungan yang diperlukan. ${ }^{64}$

Kajian penilaian risiko didasarkan pada informasi ilmiah dan dilakukan oleh tim ahli. Di dalam kajian ini juga terdapat strategi manajemen risiko yang berisikan program manajemen risiko sebagai instrumen untuk minimalisir atau mencegah risiko. Penilaian risiko ini bertujuan untuk menyediakan basis ilmiah yang memadai sebagai dasar pengambilan keputusan, tanpa harus ditujukan untuk mendapatkan pengetahuan sebanyak mungkin untuk mengesampingkan semua ketidakpastian yang ada.

Pasal 1 Protokol Cartagena memberi pengkhususan bahwa keseluruhan agenda dari adopsi protokol tersebut adalah untuk melindungi dan melestarikan keanekaragaman hayati berbasis pada pendekatan kehati-hatian. Meskipun pertanyaan utama mengenai apa yang dapat dikategorikan sebagai bahaya atau ancaman bahaya tetap muncul, kerangka pengaturan tetap diperlukan dikarenakan

64 Pasal 47 UUPPLH mensyaratkan bahwa untuk kegiatan/usaha yang berpotensi meimbulkan dampak penting bagi lingkungan, ancaman terhadap ekosistem, kehidupan, kesehatan, dan keselamatan manusia wajib melakukan analisis risiko lingkungan. Di dalam penjelasan pasalnya disebutkan anallisis ini dilakukan dalam prosedur yang antara lain digunakan untuk mengkaji pelepasan dan peredaran produk rekayasa genetik 
pemahaman terhadap bahaya dan ancaman bahaya serta nilai dari biodiversitas harus didasarkan pada konteks biologi dan sekaligus etis.

Pemerintah sebagai pembuat kebijakan tetap harus dapat membuat kebijakan atau peraturan didasarkan pada informasi ilmiah yang tersedia. Sehingga, seberapapun bentuk kebijakan/regulasi dari Pemerintah bahwa suatu komersialisasi genetik tidak dimungkinkan pelaksanaannya, tetap didasarkan pada suatu kerangka legal khusus yang telah mempertimbangkan ilmu pengetahuan, etika, aspek sosio-kultural, pertimbangan ekonomi, keindahan, maupun kriteria lain yang diperlukan. ${ }^{65}$ Isu inilah yang menjadi tugas rumah berkepanjangan dari pemerintah. Komersialisasi produk transgenik perlu dipersiapkan dengan baik, baik dalam peredarannya maupun penanganan risiko yang mungkin ditimbulkan.

Pemerintah pada konteks ini perlu menempatkan dirinya sebagai pihak yang bertugas untuk menerjemahkan informasi tentang ketidakpastian melalui artikulasi dari pertimbangan-pertimbangan normatif sehingga dapat menghasilkan satu pilihan kebijakan dan proteksi yang dibutuhkan. ${ }^{66}$ Dengan catatan bahwa jaminan atas kuantitas dan kualitas informasi, sebagaimana jaminan atas akses informasi bagi publik diakomodasi dengan baik oleh Pemerintah.

\section{Kesimpulan}

Penerapan pendekatan kehati-hatian dalam rangka proteksi terhadap komersialisasi sumber daya genetika pada dasarnya telah dilakukan sesuai amanat dari Protokol Cartagena. UU Nomor 32 Tahun 2009 pun sudah memasukkan prinsip kehati-kehatian sebagai prinsip dasar dalam perlindungan dan pengelolaan lingkungan hidup. Meskipun demikian, dalam mempersiapkan tahapan rilis komersil TPRG yang telah dimulai dengan izin peredaran pangan beberapa produk

65 Dengan adanya ego sektoral yang masih cukup tinggi, perlu suatu keterpaduan dari aspek sistem regulasi dan peraturan sehingga kajian penilaian risiko dan strategi manajemen terhadap komersialisasi genetika didasarkan pada satu kerangka spesifik, yang meliputi standar-standar normatif dan pertimbangan tentang pengaruhnya terhadap lingkungan.

66 R. Von Schomberg,. The Precautionary Principle and its Normative Challenges. dalam Chapter 2 dari E. Fisher, et al. (Eds.), Implementing the Precautionary Principle: Perspetives and Prospects. (UK: Cheltenham, 2006), hlm. 19-42 
pertanian hasil rekayasa genetika, ${ }^{67}$ masih diperlukan fasilitasi untuk diskusi yang lebih luas untuk dapat memetakan implikasi sosial, etis, dan legal dari aspek-aspek risiko yang mungkin timbul dari introdusir OHMG maupun bentuk komersialisasi genetika lainnya.

Untuk menjembatani diskursus terkait aspek risiko dari OHMG ini, perlu adanya identifikasi terhadap (i) ancaman terhadap keanekaragaman hayati seperti apa yang dianggap dapat diterima (acceptable) atau tidak, (ii) instrumen apa yang diperlukan untuk mencapai level perlindungan yang diharapkan, (iii) adakah dan data dasar apa yang dapat diterapkan sebagai pembanding dari bahaya atau ancaman bahaya yang diperkirakan, (iv) capaian normatif yang dituju untuk mengukur dampak dari OHMG, dan (v) implikasi sosio-kultural yang semestinya dihindari.

Diskursus ini juga perlu memasukkan informasi perkembangan rekayasa genetika sekarang dan rencana strategisnya di masa depan, sehingga dapat dihindari adanya kesenjangan yang cukup tinggi, antara kesiapan normatif dengan aplikasi bioteknologi di lapangan. Terlebih dengan adanya perkembangan terbaru dalam rejim hukum perlindungan keanekaragaman hayati, yaitu Protokol Nagoya tentang Access and Benefit Sharing serta Supplementary Protocol Nagoya-Kuala Lumpur tentang Redress and Liability, ${ }^{68}$ Pemerintah dihadapkan pada tuntutan legal framework yang tepat untuk menghadapi perkembangan teknologi yang cepat. Konsep "shared benefits, shared responsibility" inilah yang harus dikembangkan sekaligus dilegalkan, sehingga pemanfaatan bioteknologi oleh semua stakeholders dapat dilakukan secara baik dan dalam koridor tepat yang memungkinkan pemanfaatan secara bertanggungjawab. Beberapa hal yang harus dilakukan meliputi:

1. Menyediakan mekanisme penilaian risiko yang tidak hanya memberikan analisis yang akurat dari risiko dan ketidakpastian yang ada, tetapi juga transparan dalam hal batasan kepahaman ilmiah yang telah dimiliki.

2. Membuka kesempatan diskusi yang luas tanpa menutup kemungkinan kritikkritik ilmiah.

67 Pusat Data dan Sistem Informasi Pertanian, 2014. Buletin Konsumsi Pangan Volume 5 No. 1 Tahun 2014, hlm. 10

68 Pembahasan terpisah tentang NKL Supplementary Protocol ini dapat dilihat pada Santoso, Wahyu Yun, 2016, Bridging the Implementation of Nagoya-Kualalumpur Supplementary Protocol on Liability and Redress in Indonesia. Indonesian Law Review Vol. 6 No. 1 June 2016. 
3. Perlunya penekanan pada pendekatan yang bersifat interdisipliner dalam kajian untuk memetakan ketidakpastian ilmiah dari introdusir produk bioteknologi, terutama yang terkait dengan keanekaragaman hayati.

4. Membuka peluang partisipasi aktif dari seluruh pemangku kepentingan, sehingga dapat dicapai adanya kesepakatan yang kokoh tentang ketidakpastian ilmiah yang ada, dan sekaligus dapat memetakan kemanfaatan yang terbaik. 


\section{DAFTAR PUSTAKA}

Andow, D. A., \& Zwahlen, C. 2006. Assessing Environmental Risks of Transgenic Plants. Ecological Letters, 9, 196-214

Byrd, D. M., \& Cothern, R. 2000, Introduction to Risk Analysis. A Systematic Approach to Science-Based Decision Making. Rockville, MD, USA: Government Institutes.

CEC. European Council Directive 2001/18/EC. http://www.europa.eu.int/com$\mathrm{mm} /$ food/fs/sc/scp/out31_en.htm

CEC. Communication From the Commission on the Precautionary Principle. 2000. http:/ / europa.eu.int/comm/dgs/health_consumer/library/pub/pub07_en.pdf

Cowan, David, 2016, Frank H. Knight. Great Thinkers in Economics. London: Palgrave Macmillan,.

De Melo-Martin, I., \& Meghani, Z., 2008. Beyond Risk. EMBO Reports, 9, 302-308.

EEA: European Environment Agency. 2002. Late Lessons from Early Warnings: The Precautionary Principle 1896-2000, http://reports.eea.eu.int/environmental_issue_report_2001_22/

Gaskell, G. et.al., 2006. Europeans and Biotechnology in 2005: Pattern and Trends, Eurobarometer 64. 3, Brussels: European Commission D-G Research.

Graham, J. D., \& Wiener, J. B. 2008, The Precautionary Principle and Risk-Risk Tradeoffs: A Comment. Journal of Risk Research, 11, 465-474

Insist. 2008, Politik Pangan: Perlu Perubahan Paradigma. Yogyakarta: Penerbit INSIST,

Karlsson, M., 2006. The Precautionary Principle, Swedish Chemicals Policy and Sustainable Development. Journal of Risk Research (2006), 9, 337-360

Kriebel, D., Tickner, J., Epstein, P., Lemons, J., Levins, R., Loechler, E. L., et al., 2001. The Precautionary Principle in Environmental Science. Environmental Health Perspectives, 109, 871-876

Levidow, L. 2001, Precautionary Uncertainty: Regulating GM Crops in Europe. Social Studies of Science, 31, 842-874.

Morris, J. 2002, The Relationships Between Risk Analysis and the Precautionary Principle. Toxicology, 181-182, 127-130 
Myhr, A. I., \& Traavik, T. 2003, Sustainable Development and Norwegian Genetic Engineering Regulations: Applications, Impacts and Challenges. Journal of Agricultural and Environmental Ethics, 16, 317-335

Myhr, Anne Ingeborg, 2010. A Precautionary Approach to Genetically Modified Organisms: Challenges and Implications for Policy and Science, Journal of Agriculture and Environment Ethics (2010) 23:501-525.

Nielsen, K. M., \& Myhr, A. I. 2007. Understanding the Uncertainties Arising from Technological Inventions in Complex Biological Systems: The Case of GMOs. dalam T. Traavik \& L. C. Lim (Eds.), Biosafety Frst: Holistic Approaches to Risk and Uncertainty in Genetic Engineering and Genetically Modified Organisms. Trondheim: Tapir Academic Press.

Pusat Data dan Sistem Informasi Pertanian, 2014. Buletin Konsumsi Pangan Volume 5 No. 1 Tahun 2014.

Rio Declaration on the Environment and Development 1992

Sands, Phillipe, 2003, Principles of International Environmental Law: Second Edition, UK: Cambridge University Press,

Saunders, Peter T., 2000. Use and Abuse of Precautionary Approach. Article on the ISIS submission to US Advisory Committee on International Economic Policy (ACIEP) Biotech. Working Group, July 13, 2000.

Sandin, Per. 1999, Dimensions of the Precautionary Principle, Human and Ecological Risk Assessment: An International Journal, 5:5, 889-907, DOI:10.1080/10807039991289185

---------, 2002, The Precautionary Principle: From Theory to Practice, Stockholm: Mistra,

---------, 2004. The Precautionary Principle and the Concept of Precaution. Environmental Values, 13, 461-475.

The Nagoya Protocol on Access to Genetic Resources and the Fair and Equitable Sharing of Benefits Arising from their Utilization to the Convention on Biological Diversity.

The United Nations Convention on the Biological Diversity 1992

UNESCO COMEST. 2005. The Precautionary Principle, http://unesdoc.unesco.org/ images/ 0012/001395/139578e.pdf

Weiss, C. 2007. Defining Precaution. Environment, 49.8, 36-39. 
Wickson, F., Gillund, F. and Myhr, A. I. 2010, Treating Nanoparticles with Precaution: The Importance of Recognising Qualitative Uncertainty in Scientific Risk Assessment. dalam K. Kjølberg, F. Wickson (Eds.). 2010, Nano Meets Macro, Social Perspectives on Nanoscience and Nanotechnology. Pan Stanford Publishing.

Von Schomberg, R. 2006, The Precautionary Principle and its Normative Challenges. dalam Chapter 2 dari E. Fisher, et al. (Eds.), 2006, Implementing the Precautionary Principle: Perspetives and Prospects. UK: Cheltenham. 